\title{
The Effect of Remediation Program in Preparing Nursing Students for Licensure Examination
}

\author{
Mohamed AlMekkawi ${ }^{1}$, Firas Qatouni ${ }^{1}$, Sura Alhalalmeh ${ }^{1}$, Imad Maalouf $^{1}$, Fares Daradkeh ${ }^{1} \&$ Hadya Abdel Fattah $^{1}$ \\ ${ }^{1}$ Nursing Department, Fatima College of Health Sciences, Al Ain, UAE \\ Correspondence: Mohamed AlMekkawi, Nursing Department, Fatima College of Health Sciences, Al Ain, UAE.
}

Received: January 18, 2020

Accepted: February 15, 2020

Online Published: February 18, 2020

doi:10.5430/ijhe.v9n3p49

URL: https://doi.org/10.5430/ijhe.v9n3p49

\begin{abstract}
The challenges encountered by nursing graduates to pass the licensing exam entail considerable emotional and financial implications due to delayed employment and loss of employers' investment in graduates' preparation during orientation programs. The study aimed to identify the effectiveness of the remediation program by comparing students' performance in two comprehensive Exit Exams delivered before and after the program. A descriptive time-series evaluation design was followed to determine the effectiveness of the remediation program on students' performance. The study showed that students' overall performance improved after the delivery of the remediation program interventions. In conclusion, the use of interactive teaching strategies and formative assessments improves student nurses' overall academic performance and learning.
\end{abstract}

Keywords: remediation, exit exam, teaching strategies, critical thinking

\section{Introduction}

The quality of education is a hallmark for nursing education programs. Effective nursing education consists of complex sets of activities and skills (Morton, 2006) that provide students with the opportunity to integrate theoretical concepts learned in classroom settings with the skills and behaviors required for effective nursing practice (White, 1997). Quality teaching programs enhance nursing students' critical thinking and decision-making skills, which are essential to demonstrate nursing graduates' competence and safe practice. Giddens (2009) stated that the number of competent nursing students who can pass the licensure exams measures the quality of education programs. Therefore, if students show poor performance at these exams, they have to be exposed to several educational interventions such as remediation programs to improve their performance in areas that they have proved deficiencies (Pennington \& Spurlock, 2010).

Many countries require nursing graduates to demonstrate competence to practice nursing through the delivery of national licensure examination. In the United Arab Emirates (UAE), the department of health requires nursing licensure examination to measure the level of competency to practice nursing care. Nursing graduates have to show a standard level of competency and preparedness to pass national licensure examinations (Bonis, Taft, \& Wendler, 2007). Many countries are moving into healthcare systems with professionals capable of performing safe practice (Seldomridge \& DiBartolo, 2004). The adaptation and incorporation of high-quality teaching standards and evidence-based clinical decision-making in the nursing programs have positive effects on passing licensure exams. As such, nursing educators have a great challenge of adapting teaching-learning strategies that are relevant to the learning context and helping graduates to meet the need of the healthcare industry while preparing students to pass licensure exams (Morrison, Free, \& Newman, 2005).

The nursing graduates at Fatima College of Health Sciences (FCHS) have to pass a licensure examination conducted by the state department of health during their first six months of employment. Several graduates of the previous batches of graduates struggled to pass the licensing exam from the first attempt, and they had to repeat it more than once. The situation represented a real concern for both colleges, employers, and graduates. The inability of some of the graduates to pass the licensing exam despite repetitive tries might reflect on the quality of education delivery (Pennington \& Spurlock, 2010). Moreover, there is a considerable emotional and financial implication due to the delayed employment of the graduates (Nibert \& Young, 2008) and the loss of employers' investment of graduates' preparation during orientation programs (Messmer, Abelleira, \& Erb, 1995). To overcome the same scenario with the new batch of graduates, the faculty members decided to prepare a remediation class for students who were 'at risk' to 
fail the licensure exam after graduation.

\subsection{Aim of the Study}

The study aimed to identify the effectiveness of the remediation program by comparing students' performance in two comprehensive Exit Exams delivered before and after the program.

\section{Literature Review}

White (1997) summarized the elements required by nursing educators to deliver quality teaching. These elements were active teaching abilities, professional competence, evaluation of students, personality traits, and interpersonal relationships. Mogan and Knox (1987) indicated that teaching ability includes the skills required to convey knowledge, skills, and approaches from faculty members to students and their ability to develop conducive learning environments. Professional competence is the knowledge that faculty members possess in the subject taught. It also includes the ability to perform the necessary skills and acquire the appropriate behaviors that are essential for active learning to take place. Five elements are considered necessary for effective teaching. These elements are knowledge of the subject, concerns of students, organization, passion for the subject taught, and approachable nature.

The nursing curriculum, according to Carrick (2011), represents the curriculum content, structure, and teaching methodologies. The course content, patterns of delivery, and teaching approaches are all embedded in the processes to prepare nursing students for their nursing role after graduation. The nursing curriculum is developed to meet the requirements of licensure and accreditation authorities. The delivery of the nursing curriculum is based on nursing teaching-learning theory and research, and have to be applied in both classroom education and clinical training (Senge, 2006). Therefore, any gap in the teaching-learning process could be due to the curriculum content or curricular delivery. Accordingly, faculty members play an essential role because of their direct influence on the curricular content and teaching methods. Student's outcomes, especially their performance in licensure exams, serves as a feedback loop to determine the effectiveness of the education system.

A key consideration in education is to acknowledge different learning preferences and styles, especially among different cultures (Brownie et al., 2015). In the UAE, educators are often challenged to move students from the rote memory styles into a more constructivist approach (Brownie et al., 2015; Gunn, 2013) to enhance their critical thinking and problem-solving skills through active interaction between knowledge, skills, and contemporary learning approaches (al Mahmud, 2013). Nevertheless, moving from the old rote learning to a more constructivist approach is an essential requirement for any program to improve students' overall performance on licensure examinations (Brownie et al., 2015). The language is another complex issue and considered a challenge for nursing faculty in the UAE context because licensure examination and all nursing curricular content, instructions, and assessments are delivered in the English language, which is the second language for students. The literature recommends the use of competent English language speakers to deliver all program content and familiar with the fundamentals of teaching non-English speakers (Charlesworth, 2008).

Bonis et al. (2007) argued that nursing education is a complex process that includes a variety of educational strategies supported by the best evidence-based practices, faculty expertise, and learner needs. Accordingly, a range of educational strategies should be implemented to enhance students' performance on licensure examinations. Among these strategies is the use of study groups, delivery of multiple examinations, review sessions, time management strategies, and anxiety reduction techniques (Brownie et al., 2015; Morrison et al., 2005; Nibert \& Young, 2008). Also, faculty members have to adopt new teaching methods to improve students' comprehension and critical thinking skills in both classroom reviews and mock assessments similar to licensure examinations (DiBartolo \& Seldomridge, 2008). Delivering comprehensive examinations similar to the ones used for licensure for the students to practice, review, and assess their preparedness through a remediation program have shown successful results in improving their overall passing rates in real licensure exams (Bonis et al., 2007; Morrison et al., 2005; Brownie et al., 2015).

\section{Method}

\subsection{Participants}

The program was evaluated using a descriptive time-series evaluation design to determine the effectiveness of the remediation program on students' performance. Purposive sampling was used to select students who failed the comprehensive exit exam (Exam 1) to participate in the remediation program. Twenty-one final year nursing students enrolled at FCHS AAN campus during the academic year 2015-2016 participated in the program. 


\subsection{Procedure}

A group of nursing educators who have experience in preparing national licensure exams prepared a comprehensive exit exam (Exam 1) similar to the UAE Department of Health examination format in terms of content, quality, and complexity of questions. The exam was composed of 150 nursing questions to be completed in 3 hours. Students who failed to achieve $60 \%$ were identified as 'at-risk students' and joined a four months remediation program. The program was composed of a series of teaching, assessments, reflective and tutorial sessions, and a final exit exam (Exam 2) that resembles Exam 1. The teaching material included case studies, review material, and critical thinking exercises to enhance students' understanding of the questions as second language speakers.

\subsection{Data Analysis}

Descriptive analysis of students' test scores in Exam 1 and Exam 2, in addition to the correlation between the results, were calculated because of their importance in understanding the effect of the remediation program on students' performance. The purpose of the measurements was to identify if students' performance has improved by comparing the results of Exam 1 delivered before the remediation and Exam 2 delivered after remediation (Table 1). The mean test scores, standard error, and standard deviation for both exams were calculated. Paired samples t-Test was used to determine the difference in means before and after the remediation program. Besides, correlation tests for the two exams were used due to the continuous nature of variables to examine the possible relationship of the remediation program on students' performance.

Table 1. Nursing Students' Performance in the Two Exams

\begin{tabular}{ccc}
\hline $\begin{array}{c}\text { Students } \\
(N=21)\end{array}$ & $\begin{array}{c}\text { Results of Exam 1 } \\
\%\end{array}$ & $\begin{array}{c}\text { Results of Exam 2 } \\
\%\end{array}$ \\
\hline Student 1 & 50 & 74 \\
Student 2 & 53 & 65 \\
Student 3 & 53 & 75 \\
Student 4 & 45 & 61 \\
Student 5 & 59 & 81 \\
Student 6 & 58 & 75 \\
Student 7 & 48 & 77 \\
Student 8 & 56 & 70 \\
Student 9 & 47 & 69 \\
Student 10 & 33 & 64 \\
Student 11 & 56 & 75 \\
Student 12 & 56 & 69 \\
Student 13 & 50 & 83 \\
Student 14 & 58 & 72 \\
Student 15 & 41 & 72 \\
Student 16 & 52 & 76 \\
Student 17 & 44 & 79 \\
Student 18 & 47 & 71 \\
Student 19 & 52 & 73 \\
Student 20 & 45 & 76 \\
Student 21 & 44 & 62 \\
\hline
\end{tabular}

\section{Results}

Table 2 shows the descriptive statistics for the two exams. The mean test score of Exam 1 was 49.91 (SD = 6.5), and Exam 2 was $72.33(\mathrm{SD}=5.89)$. The passing score for both exams was 60. Students' test scores in Exam 2 were much better than Exam 1, and therefore it was clear that the average performance of students increased after the delivery of the remediation program. 
Table 2. Descriptive Statistics of the Scores the two Exams

\begin{tabular}{cccc}
\hline Exam 1 & \multicolumn{3}{c}{ Exam 2 } \\
\hline Mean & 49.91 & Mean & 72.33 \\
Standard Error & 1.42 & Standard Error & 1.29 \\
Standard Deviation & 6.50 & Standard Deviation & 5.89 \\
Minimum & 33.33 & Minimum & 61.00 \\
Maximum & 59.61 & Maximum & 83.00 \\
$N$ & 21 & $N$ & 21 \\
Confidence Level (95.0\%) & 2.96 & Confidence Level $(95.0 \%)$ & 2.68 \\
\hline
\end{tabular}

Table 3 and Figure 1 show that the test scores were positively correlated $(r=0.369)$, and there was a significant variance between the test scores of the two exams ( $t$ Stat $=14.72, p<0.001)$. Therefore, the results suggest that students' overall performance was significantly improved after the delivery of the remediation program interventions.

Table 3. Paired t-Test

\begin{tabular}{ccc}
\hline & Exam 1 & Exam 2 \\
\hline Mean & 49.91 & 72.33 \\
Observations & 21 & 21 \\
\hline Pearson Correlation & 0.369 & \\
$\mathrm{t}$ Stat & -14.72 & \\
$\mathrm{P}(\mathrm{T}<=\mathrm{t})$ two-tail & $3.39942 \mathrm{E}-12$ & \\
$\mathrm{t}$ Critical two-tail & 2.085 & \\
\hline
\end{tabular}

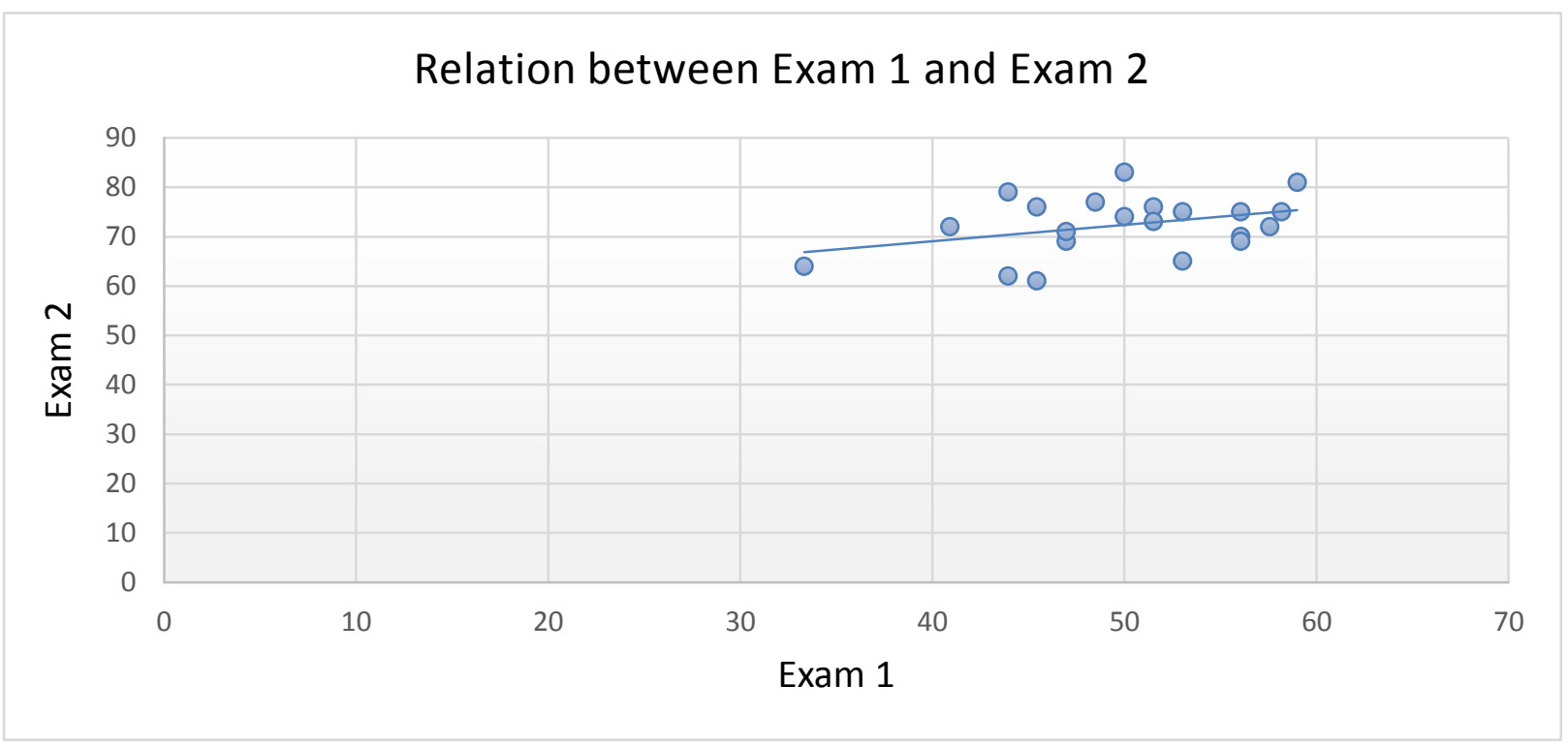

Figure 1. Correlation between Exam 1 and Exam 2 before and after the remedial program

\section{Discussion}

It was noted that there is little empirical evidence existing in the region that supports the efficacy of remediation programs to improve final year nursing students' performance in licensure-standardized examinations. This study aimed to identify the effectiveness of the remediation program delivered to the final year nursing students during the academic year 2015-2016. The four months remediation program primarily addressed test-taking strategies, students' anxiety, and time management through the introduction of a series of case studies, review material, formative assessments, and critical thinking exercises. 
The results of this study showed that the average performance of students increased after the delivery of the remediation program. Statistical tests displayed a significant variance between the scores of the two exams, $t$-Test (14.72) and $\mathrm{P}<0.001$. This finding suggested that students' overall performance was significantly improved after the delivery of program interventions. The results are consistent with Sifford and McDaniel's study, who had a 38.3\% improvement in the examination results in students who followed remedial interventions (Sifford \& McDANIEL, 2007). In another study, Horton, Polek, and Hardie (2012) found that $13.1 \%$ difference in the success rate of a group of students who attended a remediation program. To encourage deep learning, nursing students need to have teaching methods that target their higher order of thinking (Carrick, 2011). The method of interactive teaching strategies and formative assessments demonstrated significant development of student nurses' performance and overall learning (Biggs, 2011).

The current study findings support the need for control group design to minimize the threats to the study validity. The use of larger sample size and more nursing schools in different geographic areas might improve the study generalizability. Therefore, it is recommended to perform more studies in the future to identify types of successful remediation across nursing programs. The use of qualitative designs might also be helpful to determine students' perceptions regarding this type of program and could be useful to determine different perspectives of the problem.

\section{Conclusion}

The findings of the study indicated improved students' average test scores of the comprehensive exit exam after the delivery of four months remediation program. The use of interactive teaching strategies and formative assessments improves student nurses' overall academic performance and learning. Incorporating high-quality teaching methods in the nursing programs will have positive effects on students' performance at the licensure exams. Therefore, nursing schools have a great responsibility to adapt teaching and learning strategies that are relevant to the learning context and helpful to meet the needs of the healthcare industry while preparing students to pass the licensure exams.

\section{References}

al Mahmud, A. (2013). Constructivism and reflectivism as the logical counterparts in TESOL: Learning theory versus teaching methodology. TEFLIN journal, 24(2), 237-257.

Biggs, J. B. (2011). Teaching for quality learning at university: What the student does. McGraw-hill education (UK).

Bonis, S., Taft, L. \& Wendler, M. C. (2007). Strategies to promote success on the NCLEX-RN®: an evidence-based approach using the ACE Star model of knowledge transformation. Nursing education perspectives, 28(2), 82-87.

Brownie, S., Williams, G., Barnewall, K., Bishaw, S., Cooper, J. L., Robb, W. \& Kuzemski, D. (2015). Pedagogy and culture: An educational initiative in supporting UAE nursing graduates prepare for a high-stakes nurse licensing examination. International Journal of Higher Education, 4(1), 200. https://doi.org/10.5430/ijhe.v4n1p200

Carrick, J. A. (2011). Student achievement and NCLEX-RN success: Problems that persist. Nursing education perspectives, 32(2), 78-83. https://doi.org/10.5480/1536-5026-32.2.78

Charlesworth, Z. M. (2008). Learning styles across cultures: suggestions for educators. Education Training, 50(2), 115-127. https://doi.org/10.1108/00400910810862100

DiBartolo, M. C. \& Seldomridge, L. A. (2008). A review of intervention studies to promote NCLEX-RN success of baccalaureate students. Nurse Educator, 33(5), 78S-83S. https://doi.org/10.1097/01.NCN.0000336449.70283.16

Giddens, J. F. (2009). Changing paradigms and challenging assumptions: Redefining quality and NCLEX-RN pass rates. Journal of Nursing Education, 48(3), 123-124. https://doi.org/10.3928/01484834-20090301-04

Gunn, C. L. (2013). Enhancing teaching and learning in higher education in the United Arab Emirates: Reflections from the classroom. Cambridge Scholars Publishing.

Horton, C., Polek, C. \& Hardie, T. L. (2012). The relationship between enhanced remediation and NCLEX success. Teaching and Learning in Nursing, 7(4), 146-151. https://doi.org/10.1016/j.teln.2012.06.002

Messmer, P. R., Abelleira, A. \& Erb, P. S. (1995). Code 50: An orientation matrix to track orientation cost. Journal of nursing staff development: JNSD, 11(5), 261-264.

Mogan, J. \& Knox, J. E. (1987). Characteristics of 'best'and 'worst'clinical teachers as perceived by university nursing faculty and students. Journal of Advanced nursing, 12(3), 331-337. https://doi.org/10.1111/j.1365-2648.1987.tb01339.x 
Morrison, S., Free, K. W. \& Newman, M. (2005). Do progression and remediation policies improve NCLEX-RN pass rates? Nurse Educator, 30(3S), 46S-48S. https://doi.org/10.1097/00006223-200505001-00011

Morton, A. M. (2006). Improving NCLEX scores with structured learning assistance. Nurse Educator, 31(4), 163-165. https://doi.org/10.1097/00006223-200607000-00009

Nibert, A. T. \& Young, A. (2008). A third study on predicting NCLEX success with the HESI Exit Exam. CIN: Computers, Informatics, Nursing, 26(5), 21S-27S. https://doi.org/10.1097/01.NCN.0000336438.16918.c2

Pennington, T. D. \& Spurlock, D. (2010). A systematic review of the effectiveness of remediation interventions to improve NCLEX-RN pass rates. Journal of Nursing Education, 49(9), 485-492. https://doi.org/10.3928/01484834-20100630-05

Seldomridge, L. A. \& DiBartolo, M. C. (2004). Can success and failure be predicted for baccalaureate graduates on the computerized NCLEX-RN? Journal of Professional Nursing, 20(6), 361-368. https://doi.org/10.1016/j.profnurs.2004.08.005

Senge, P. M. (2006). The fifth discipline: The art and practice of the learning organization: Broadway Business.

Sifford, S. \& McDANIEL, D. M. (2007). Results of a remediation program for students at risk for failure on the NCLEX exam. Nursing education perspectives, 28(1), 34-36.

White, L. C. (1997). Perceptions of effective clinical teachers in practical nursing programs. University of Alabama. 